\title{
Electronic structure of spinel oxides: zinc aluminate and zinc gallate
}

\author{
Suresh K Sampath, D G Kanhere † and Ravindra Pandey \\ Department of Physics, Michigan Technological University, Houghton, MI-49931, USA
}

Received 20 October 1998

\begin{abstract}
The electronic structure of zinc aluminate $\left(\mathrm{ZnAl}_{2} \mathrm{O}_{4}\right)$ and that of zinc gallate $\left(\mathrm{ZnGa}_{2} \mathrm{O}_{4}\right)$ were studied by the self-consistent tight-binding linearized muffin-tin orbital method with the atomic sphere approximation. The calculated results predict these zinc-based spinel oxides to be direct-gap materials. The direct gap at $\Gamma$ is found to be $4.11 \mathrm{eV}$ for $\mathrm{ZnAl}_{2} \mathrm{O}_{4}$ and $2.79 \mathrm{eV}$ for $\mathrm{ZnGa}_{2} \mathrm{O}_{4}$. With reference to the calculated band gap of $5.36 \mathrm{eV}$ for $\mathrm{MgAl}_{2} \mathrm{O}_{4}$, the systematic decrease in the gap is attributed to the presence of $3 \mathrm{~d}$ orbitals of $\mathrm{Zn}$ and $\mathrm{Ga}$ and the associated $\mathrm{p}-\mathrm{d}$ hybridization in the upper valence band of zinc aluminate and gallate. Comparison of the contour maps of the electron localization function of $\mathrm{ZnAl}_{2} \mathrm{O}_{4}$ and $\mathrm{ZnGa}_{2} \mathrm{O}_{4}$ with that of $\mathrm{MgAl}_{2} \mathrm{O}_{4}$ clearly shows the bonding to be less ionic in the zinc-based spinel oxides. Finally, the calculations yield a smaller electron effective mass for zinc gallate as compared to that for zinc aluminate, suggesting a higher mobility of electrons in gallate.
\end{abstract}

\section{Introduction}

Zinc aluminate $\left(\mathrm{ZnAl}_{2} \mathrm{O}_{4}\right)$ and zinc gallate $\left(\mathrm{ZnGa}_{2} \mathrm{O}_{4}\right)$ are members of the class of inorganic materials called spinels. They have a close-packed face-centred-cubic structure [1] with $F d 3 m$ space group symmetry. These spinel oxides are wide-band-gap semiconductors; the optical band gaps are reported [2] to be about 3.8 and $4.1 \mathrm{eV}$ for $\mathrm{ZnAl}_{2} \mathrm{O}_{4}$ and $\mathrm{ZnGa}_{2} \mathrm{O}_{4}$ respectively. Furthermore, in the polycrystalline form, they are found to be highly reflective from $300 \mathrm{~nm}$ which is well within the ultraviolet regime of the spectrum. This has attracted considerable interest amongst researchers for a variety of applications. For example, they are being studied as candidate materials for reflective optical coatings in aerospace applications [3]. Additionally, zinc gallate is proposed as phosphor material [4] and ultraviolet-transport electroconductive oxide [5].

There has been considerable work involving both experimental and theoretical methods on spinel oxides like magnesium aluminate $\left(\mathrm{MgAl}_{2} \mathrm{O}_{4}\right)$, but there are very few reported studies on zinc aluminate $\left(\mathrm{ZnAl}_{2} \mathrm{O}_{4}\right)$ and zinc gallate $\left(\mathrm{ZnGa}_{2} \mathrm{O}_{4}\right)$. In particular, the known properties of these materials are just the crystal structure [1] and the optical spectra [2,4,5], and the electronic properties are relatively unknown.

On the theoretical front, we are not aware of any studies except that leading to the prediction of the stability of the normal spinel structure over the inverse structure for $\mathrm{ZnAl}_{2} \mathrm{O}_{4}$ [6]. We have therefore embarked upon a detailed theoretical study of these zinc-based spinel oxides. In an earlier work, we have reported the results of an atomistic simulation study [7] that included derivation of interatomic potentials, and determination of the equation of state and

$\dagger$ Permanent address: Department of Physics, University of Pune, Pune, 411007, India. 
compressibility behaviour at the octahedral and tetrahedral sites in the spinel lattice, and the energetics of point defects in $\mathrm{ZnAl}_{2} \mathrm{O}_{4}$ and $\mathrm{ZnGa}_{2} \mathrm{O}_{4}$. In the present work, we focus our attention on their electronic properties and report the results of electronic structure calculations within the framework of the local density approximation (LDA) to the density functional theory.

This paper is organized as follows. Section 2 briefly describes the method and relevant computational parameters used in the calculations. In section 3 , we discuss the calculated results for electronic properties of these oxides in terms of band structure, density of states and electron effective mass. Finally, we give summary of the work in section 4.

\section{Method}

We employ the tight-binding muffin-tin orbital (TB-LMTO) method in the atomic sphere approximation (ASA) for electronic structure calculations. Since the standard LMTO-ASA method [8] and its localized representation the TB-LMTO method $[9,10]$ have been well described in the literature, we confine our discussions here to the relevant computational details of the method.

In the ASA, the crystal is divided into space-filling and therefore slightly overlapping spheres centred on each of the atomic sites. A total of 18 empty spheres were used for filling the space of the unit cell and they were of three different types. In all of the cases, the $\mathrm{Zn} \mathrm{3d}$ and $\mathrm{Ga} 3 \mathrm{~d}$ electrons were always treated as the band electrons. Calculations were performed using the von Barth-Hedin local exchange-correlation potential [11]. The method is scalar relativistic, and combined correction has been taken into account. The self-consistency was obtained using $256 k$-points in the irreducible zone. The tetrahedron method of integration with corrections due to linear approximation for the bands inside each tetrahedron was used for the Brillouin integration.

\section{Results and discussion}

\subsection{Structural properties}

The normal spinel lattice is characterized by the lattice constant $a$ and the internal parameter $u$ (which specifies the position of the oxygen anion in the cell). In the total-energy calculations, the lattice constant $a$ was minimized at the experimental value of $u$ which is reported [1] to take the values 0.389 and 0.387 for $\mathrm{ZnAl}_{2} \mathrm{O}_{4}$ and $\mathrm{ZnGa}_{2} \mathrm{O}_{4}$ respectively. The potential energy surface generated was then fitted to the Vinet equation of state to obtain the equilibrium structural parameters (volume, bulk modulus and its pressure derivative) for zinc aluminate and gallate.

The optimized values of the lattice constant turn out to be 7.91 and $8.174 \AA$, as compared to the experimental values of 8.086 and $8.33 \AA$ for $\mathrm{ZnAl}_{2} \mathrm{O}_{4}$ and $\mathrm{ZnGa}_{2} \mathrm{O}_{4}$ respectively. For both spinel oxides, our calculated values of $a$ are within $2 \%$ of the corresponding experimental values. Given that the divalent cation is the same in both spinels, the ion-size difference between $\mathrm{Ga}^{3+}$ and $\mathrm{Al}^{3+}$ should be responsible for the larger $a$-parameter in $\mathrm{ZnGa}_{2} \mathrm{O}_{4}$ as compared to $\mathrm{ZnAl}_{2} \mathrm{O}_{4}$.

The calculated values of the bulk modulus $\left(B_{0}\right)$ and its pressure derivative $\left(B_{0}^{\prime}\right)$, evaluated at zero pressure, compare favourably with those obtained earlier in an atomistic simulation study. [7] Their values $\left(B_{0}\right.$ and $\left.B_{0}^{\prime}\right)$ are predicted to be (262 GPa, 4.43) and (243 GPa, 2.71) for $\mathrm{ZnAl}_{2} \mathrm{O}_{4}$ and $\mathrm{ZnGa}_{2} \mathrm{O}_{4}$ respectively. No experimental data on these oxides are available for comparison with the predicted values. 


\subsection{Electronic properties}

Now we discuss our results pertaining to the electronic properties of $\mathrm{ZnAl}_{2} \mathrm{O}_{4}$ and $\mathrm{ZnGa}_{2} \mathrm{O}_{4}$ via the energy bands, density of states and effective mass. To provide a benchmark for the calculated electronic properties of $\mathrm{ZnAl}_{2} \mathrm{O}_{4}$ and $\mathrm{ZnGa}_{2} \mathrm{O}_{4}$, we include the TB-LMTO results for $\mathrm{MgAl}_{2} \mathrm{O}_{4}$ which has been extensively studied $[12,13]$. A comparison between the electronic properties of $\mathrm{MgAl}_{2} \mathrm{O}_{4}$ and $\mathrm{ZnAl}_{2} \mathrm{O}_{4}$ would facilitate assessing the role of $\mathrm{d}$ electrons in the composition of the valence and conduction bands of the spinel oxides. Furthermore, we can also study the ion-size effect $\left(\mathrm{Al}^{3+}\right.$ versus $\left.\mathrm{Ga}^{3+}\right)$ by comparing the electronic properties of $\mathrm{ZnAl}_{2} \mathrm{O}_{4}$ and $\mathrm{ZnGa}_{2} \mathrm{O}_{4}$.

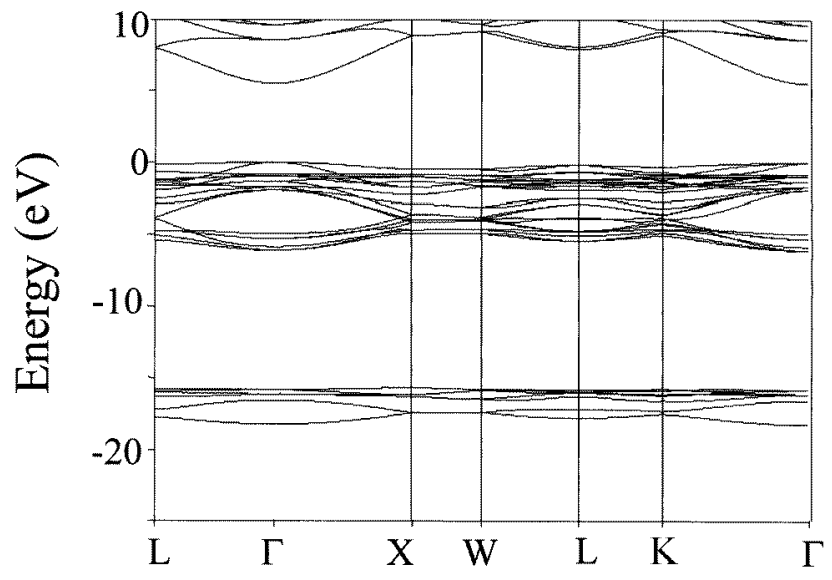

Figure 1. The band structure of $\mathrm{MgAl}_{2} \mathrm{O}_{4}$.

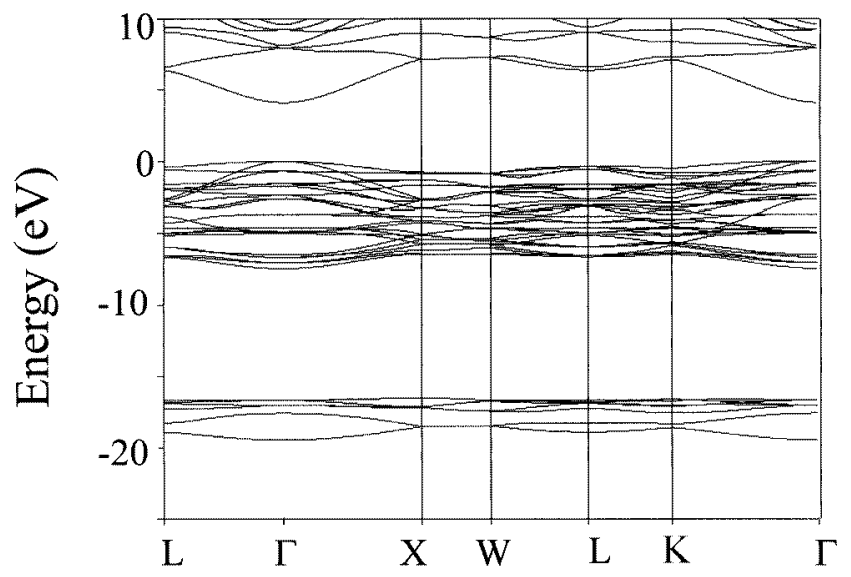

Figure 2. The band structure of $\mathrm{ZnAl}_{2} \mathrm{O}_{4}$.

The energy bands of $\mathrm{MgAl}_{2} \mathrm{O}_{4}, \mathrm{ZnAl}_{2} \mathrm{O}_{4}$ and $\mathrm{ZnGa}_{2} \mathrm{O}_{4}$ are given in figures 1-3. Accordingly, the spinel oxides are predicted to be direct-gap materials. Both the top of the valence band and the bottom of the conduction band are found to be at $\Gamma$. The minimum (direct) gaps turn out to be 5.36, 4.11 and $2.79 \mathrm{eV}$ for $\mathrm{MgAl}_{2} \mathrm{O}_{4}, \mathrm{ZnAl}_{2} \mathrm{O}_{4}$ and $\mathrm{ZnGa}_{2} \mathrm{O}_{4}$ respectively. Experimentally, the gap in $\mathrm{MgAl}_{2} \mathrm{O}_{4}$ is reported [14] to be about $7.8 \mathrm{eV}$, while those for 


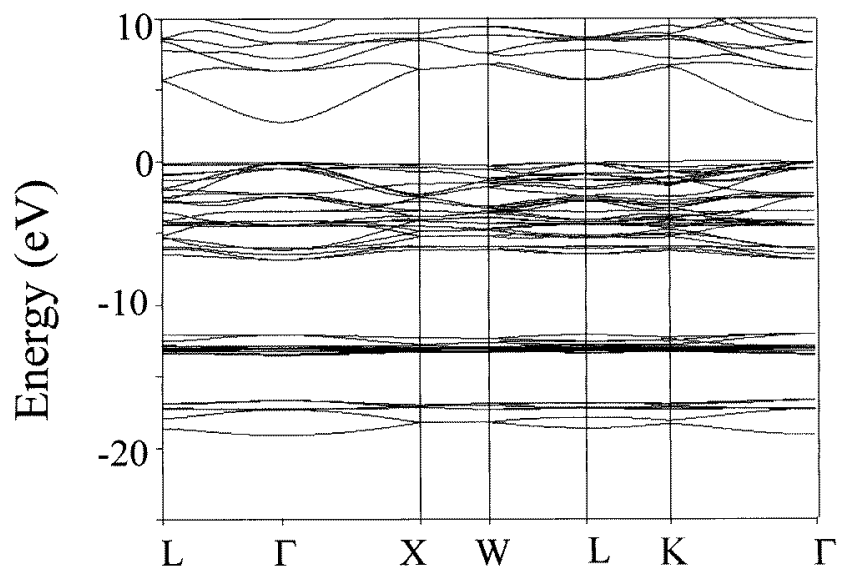

Figure 3. The band structure of $\mathrm{ZnGa}_{2} \mathrm{O}_{4}$.

Table 1. Electronic properties of $\mathrm{MgAl}_{2} \mathrm{O}_{4}, \mathrm{ZnAl}_{2} \mathrm{O}_{4}$ and $\mathrm{ZnGa}_{2} \mathrm{O}_{4}$.

\begin{tabular}{llll}
\hline & $\mathrm{MgAl}_{2} \mathrm{O}_{4}$ & $\mathrm{ZnAl}_{2} \mathrm{O}_{4}$ & $\mathrm{ZnGa}_{2} \mathrm{O}_{4}$ \\
\hline Lattice parameter $(\AA)$ & 7.934 & 7.91 & 8.174 \\
& & & \\
Direct gap, eV & & & \\
$\left(\Gamma_{1 \mathrm{c}}-\Gamma_{15 \mathrm{v}}\right)$ & 5.36 & 4.11 & 2.79 \\
$\left(\mathrm{~L}_{1 \mathrm{c}}-\mathrm{L}_{3 \mathrm{v}}\right)$ & 7.85 & 6.77 & 5.80 \\
$\left(\mathrm{~K}_{1 \mathrm{c}}-\mathrm{K}_{2 \mathrm{v}}\right)$ & 8.84 & 7.64 & 6.62 \\
$\left(\mathrm{X}_{1 \mathrm{c}}-\mathrm{X}_{5 \mathrm{v}}\right)$ & 9.02 & 7.94 & 6.71 \\
Indirect gap, eV & & & \\
$\left(\mathrm{L}_{1 \mathrm{c}}-\Gamma_{15 \mathrm{v}}\right)$ & & & \\
$\left(\mathrm{K}_{1 \mathrm{c}}-\Gamma_{15 \mathrm{v}}\right)$ & 7.69 & 6.38 & 5.73 \\
$\left(\mathrm{X}_{1 \mathrm{c}}-\Gamma_{15 \mathrm{v}}\right)$ & 8.54 & 7.12 & 6.60 \\
& 8.60 & 7.17 & 6.51 \\
$\mathrm{Upper} \mathrm{valence}$ & 6.28 & 7.59 & 6.81 \\
bandwidth & & & \\
Electron effective & & & \\
mass, eV & & & \\
$\Gamma-\mathrm{X}$ & 0.36 & 0.36 & 0.22 \\
$\Gamma-\mathrm{L}$ & 0.38 & 0.32 & 0.21 \\
$\Gamma-\mathrm{K}$ & 0.39 & 0.38 & 0.23 \\
\hline
\end{tabular}

$\mathrm{ZnAl}_{2} \mathrm{O}_{4}$ and $\mathrm{ZnGa}_{2} \mathrm{O}_{4}$ [2] are about 3.8-3.9 and 4.1-4.3 eV respectively. For $\mathrm{ZnGa}_{2} \mathrm{O}_{4}$, another set of diffuse reflectance measurements lead to an estimate of the gap of about $5 \mathrm{eV}$ [5]. Although the LDA calculations underestimate the band gap relative to experiments, we note here that the band gaps of $\mathrm{ZnAl}_{2} \mathrm{O}_{4}$ and $\mathrm{ZnGa}_{2} \mathrm{O}_{4}$ were derived from reflectance measurements of powder samples and may therefore require correction for the particle-size dependence of light scattering. Generally, lowering of the band gap is expected with the substitution of heavier cations (e.g. $\mathrm{Zn}$ for $\mathrm{Mg}$ or $\mathrm{Ga}$ for $\mathrm{Al}$ ) in a series of compounds which are structurally isomorphous. The calculated results in fact show a lowering of the gap from $\mathrm{MgAl}_{2} \mathrm{O}_{4}$ to 
$\mathrm{ZnAl}_{2} \mathrm{O}_{4}$ to $\mathrm{ZnGa}_{2} \mathrm{O}_{4}$ (table 1).

The electronic structure of $\mathrm{MgAl}_{2} \mathrm{O}_{4}$ has been previously reported [12]; in deriving it, the orthogonalized linear combination of atomic orbitals (OLCAO) (within the LDA approximation) method was used. There is overall agreement between the TB-LMTO and the OLCAO calculations regarding the composition of valence and conduction bands. However, the OLCAO calculations reported the valence-band maximum to be along the $\Gamma-\mathrm{K}$ axis, predicting $\mathrm{MgAl}_{2} \mathrm{O}_{4}$ to be an indirect-gap material, in contrast to the prediction of a minimum direct gap in the present study. As pointed out in the OLCAO study, the difference between the direct and indirect gap was about $0.004 \mathrm{eV}$ which is well within the accuracy of the OLCAO calculations. Note that the optical reflectivity measurements [14] reported the minimum band gap of $\mathrm{MgAl}_{2} \mathrm{O}_{4}$ to be direct at $\Gamma$.

Figures 4-6 give the total and partial (site-projected) densities of states (DOS) for the spinel oxides. In $\mathrm{MgAl}_{2} \mathrm{O}_{4}$, the upper valence band is composed mostly of $\mathrm{O} 2 \mathrm{p}$ orbitals with

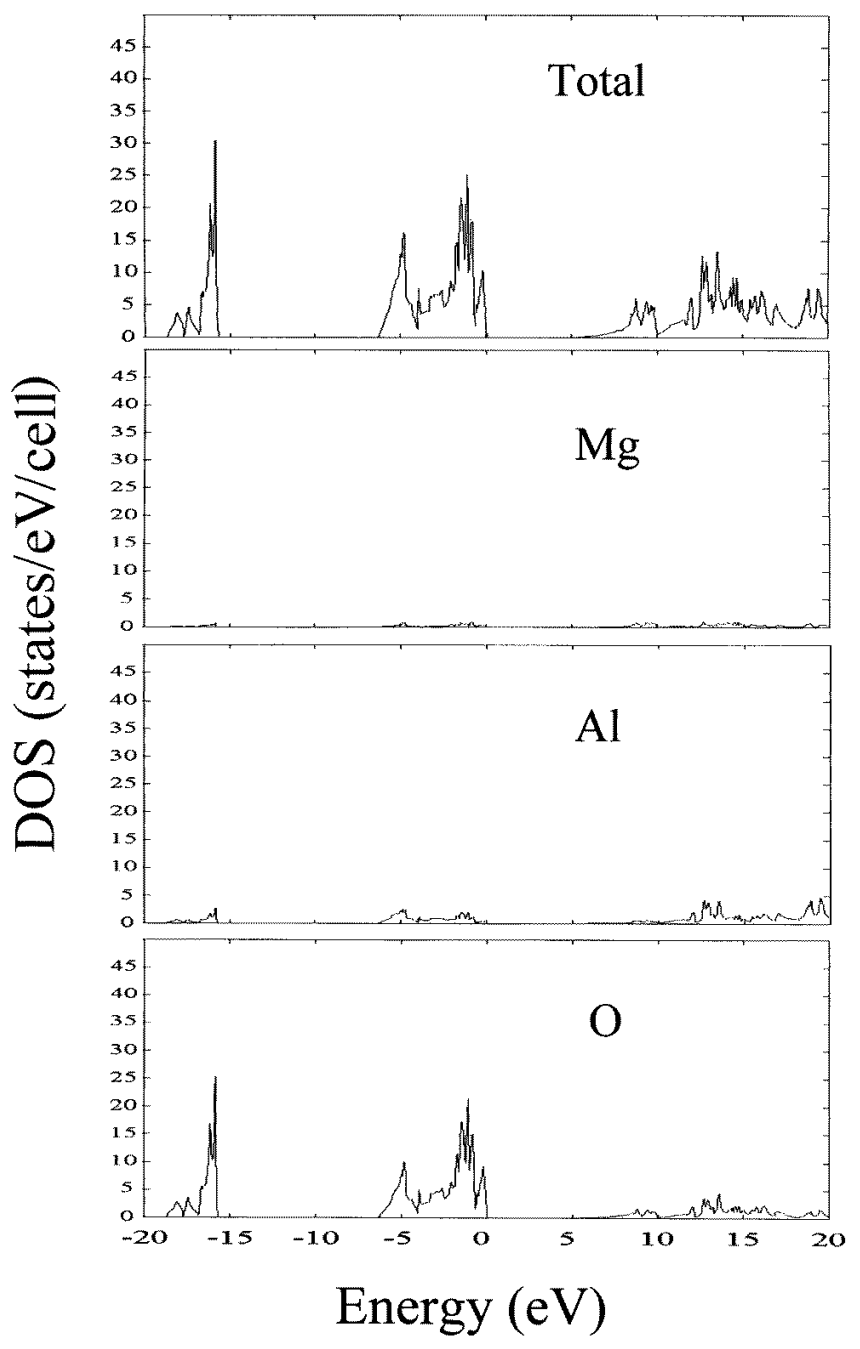

Figure 4. Total and partial densities of states of $\mathrm{MgAl}_{2} \mathrm{O}_{4}$. 


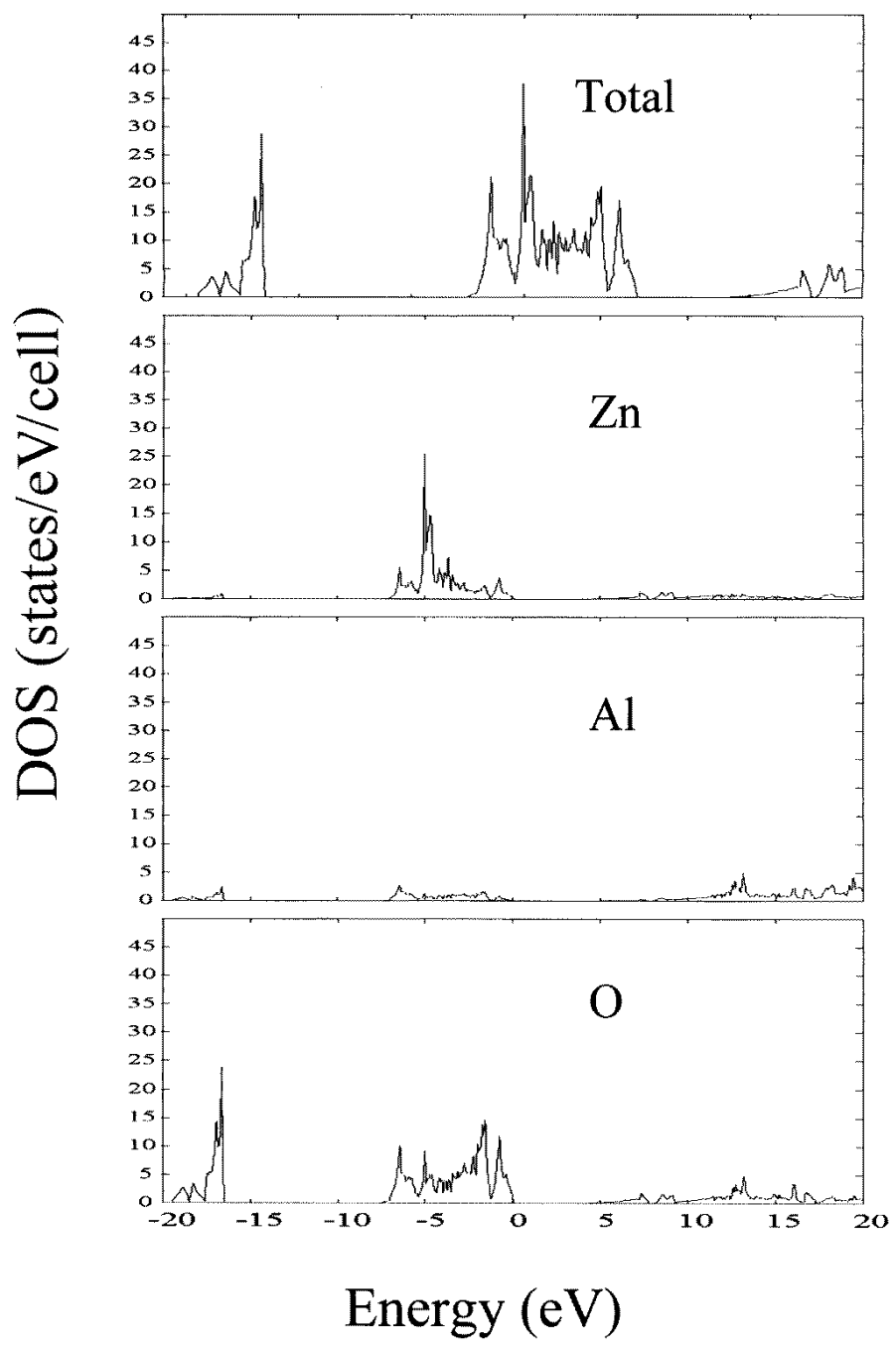

Figure 5. Total and partial densities of states of $\mathrm{ZnAl}_{2} \mathrm{O}_{4}$.

the width of $6.3 \mathrm{eV}$. The replacement of $\mathrm{Mg}$ with $\mathrm{Zn}$ brings the contributions from $\mathrm{Zn} \mathrm{3d}$ electrons to the upper valence band in $\mathrm{ZnAl}_{2} \mathrm{O}_{4}$. Instead of the $\mathrm{O} 2 \mathrm{p}$-dominated band, the zinc $3 \mathrm{~d}$ band appears inside the upper valence band and as a consequence the bandwidth broadens to $7.6 \mathrm{eV}$. In both cases, the bottom of the conduction band is composed of $\mathrm{s}$ and $\mathrm{p}$ states. It is therefore expected that changes in the electronic properties of $\mathrm{ZnAl}_{2} \mathrm{O}_{4}$ as compared to those of $\mathrm{MgAl}_{2} \mathrm{O}_{4}$ would solely be due to the mixing of $\mathrm{Zn} 3 \mathrm{~d}$ and $\mathrm{O} 2 \mathrm{p}$ orbitals. We note here that the structural parameters of $\mathrm{MgAl}_{2} \mathrm{O}_{4}$ and $\mathrm{ZnAl}_{2} \mathrm{O}_{4}$ are nearly the same (e.g. $R_{\mathrm{Mg}-\mathrm{O}}=1.896 \AA$, $R_{\mathrm{Zn}-\mathrm{O}}=1.904 \AA$ ).

The role of $\mathrm{d}$ states in defining the electronic properties of the II-VI semiconductors has been extensively discussed by Wei and Zunger [15] who have concluded that the p- $d$ hybridization at $\Gamma$ repels the valence-band maximum upwards without affecting the conduction-band minimum in several II-VI semiconductors. In the present study, the hybridization of $\mathrm{Zn} 3 \mathrm{~d}$ with the $\mathrm{O} 2 \mathrm{p}$ orbitals is clearly evident (figure 5). Hence the lowering 


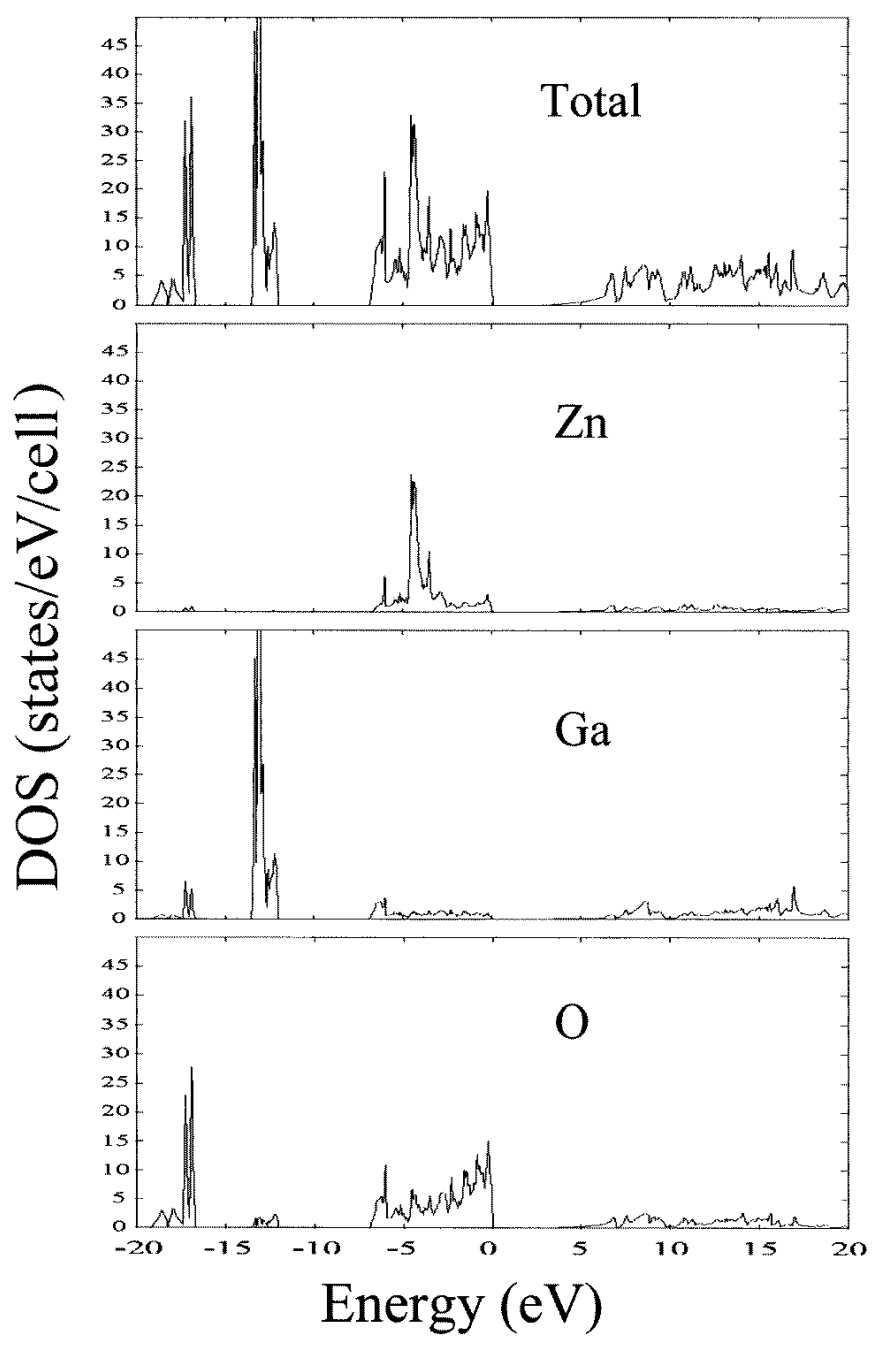

Figure 6. Total and partial densities of states of $\mathrm{ZnGa}_{2} \mathrm{O}_{4}$.

of the calculated gap at $\Gamma$ from $5.36\left(\mathrm{MgAl}_{2} \mathrm{O}_{4}\right)$ to $4.11 \mathrm{eV}\left(\mathrm{ZnAl}_{2} \mathrm{O}_{4}\right)$ can be attributed to the

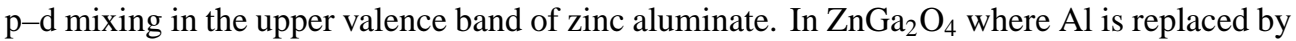
$\mathrm{Ga}$, a narrow $\mathrm{Ga} 3 \mathrm{~d}$ band appears between the upper valence band and the $\mathrm{O} 2 \mathrm{~s}$ band (figure 6). This appearance of the $\mathrm{Ga} 3 \mathrm{~d}$ band in addition to the $\mathrm{Zn} 3 \mathrm{~d}$ band in the upper valence band further provides the $\mathrm{p}-\mathrm{d}$ repulsion for the valence-band maximum at $\Gamma$, thereby reducing the gap to $2.79 \mathrm{eV}$.

In the spinels studied here, the valence-band maximum is flat, representing the rather large effective mass for the holes. On the other hand, calculations show that the electron effective mass is much smaller in $\mathrm{ZnGa}_{2} \mathrm{O}_{4}$ than that in $\mathrm{ZnAl}_{2} \mathrm{O}_{4}$. However, the electron effective mass remains essentially the same in $\mathrm{MgAl}_{2} \mathrm{O}_{4}$ and $\mathrm{ZnAl}_{2} \mathrm{O}_{4}$ (table 1). Thus our calculations predict a higher mobility of electrons in $\mathrm{ZnGa}_{2} \mathrm{O}_{4}$ relative to both $\mathrm{MgAl}_{2} \mathrm{O}_{4}$ and $\mathrm{ZnAl}_{2} \mathrm{O}_{4}$. Note that our calculated value of the electron effective mass is in agreement with the OLCAO-LDA results of 0.44 . 
A further insight into the bonding characteristics can be gained by examining the contour plots of the electron localization functions (ELF), defined as [16]

$$
\operatorname{ELF}(\vec{r})=\left[1+\left(\frac{D}{\left(C_{F}\right) \rho^{5 / 3}(\vec{r})}\right)^{2}\right]^{-1}
$$

where

$$
\begin{aligned}
D & =T_{0}-\frac{|\nabla \rho|^{2}}{8 \rho} \\
C_{F} & =\frac{3}{10}\left(3 \pi^{2}\right)^{2 / 3} \\
T_{0} & =\frac{1}{2} \sum_{i}\left|\nabla \psi_{i}{ }^{2}\right| .
\end{aligned}
$$

It may be noted that the ELFs represent a measure of calibration of the degree of the electron localization with respect to the uniform density. The function can take values between 0 and 1 with the value of 1 representing complete localization. Thus, the ELFs are a useful interpretative tool for investigating the bonding characteristics of the system. Since we use the TB-LMTO method in the present study, we are well aware of its limitation of underestimating directionality in the electron distribution in solids. We will therefore restrict ourselves to making a comparative analysis of the variation in the bonding of these oxides.

The contour plots of the ELFs for $\mathrm{MgAl}_{2} \mathrm{O}_{4}, \mathrm{ZnAl}_{2} \mathrm{O}_{4}$ and $\mathrm{ZnGa}_{2} \mathrm{O}_{4}$ are shown in figures 7-9. These contours which are projected on a plane parallel to the (110) plane show a strong localized region around the oxygens. They also show the differences in the nature of bonding among these spinels. In particular, the ELF is spherically symmetric in $\mathrm{MgAl}_{2} \mathrm{O}_{4}$ indicating that the bonding is dominated by the ionic component. Significant distortions in the ELF contours are observed when we replace $\mathrm{Mg}$ with $\mathrm{Zn}$. Comparison of the $\mathrm{Mg}-\mathrm{O}$ (figure 7) and $\mathrm{Zn}-\mathrm{O}$ bond (figure 8 ) suggests reduced ionicity in the bonding for zinc aluminate. This effect is clearly due to the participation of the $\mathrm{Zn} 3 \mathrm{~d}$ orbitals in the bonding. On the other hand, comparison between the $\mathrm{Al}-\mathrm{O}$ bond (figure 8 ) and the $\mathrm{Ga}-\mathrm{O}$ bond (figure 9 ) reveals a smaller effect on the bonding due to the localized $\mathrm{Ga} 3 \mathrm{~d}$ orbitals in $\mathrm{ZnGa}_{2} \mathrm{O}_{4}$. Furthermore, we notice that the contour plots show the presence of an empty channel with a relatively small charge

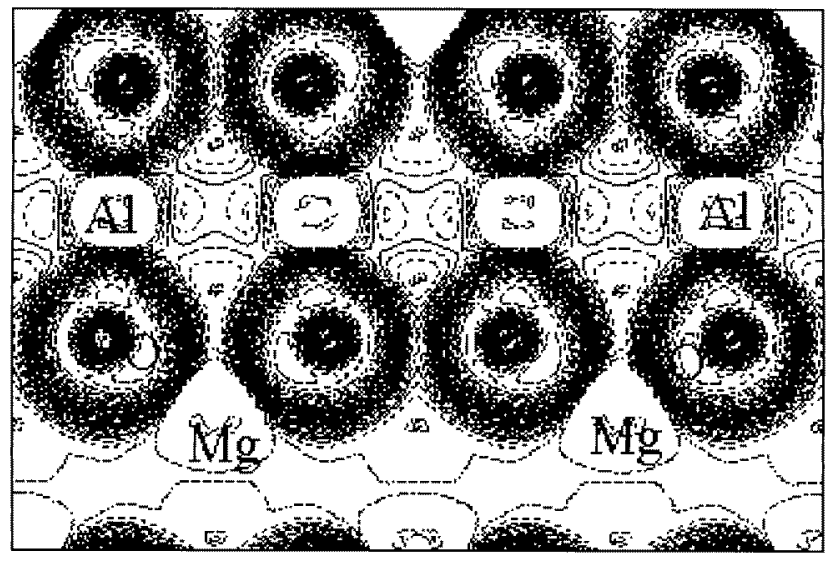

Figure 7. The ELF contour plot of $\mathrm{MgAl}_{2} \mathrm{O}_{4}$ along the (110) plane. 


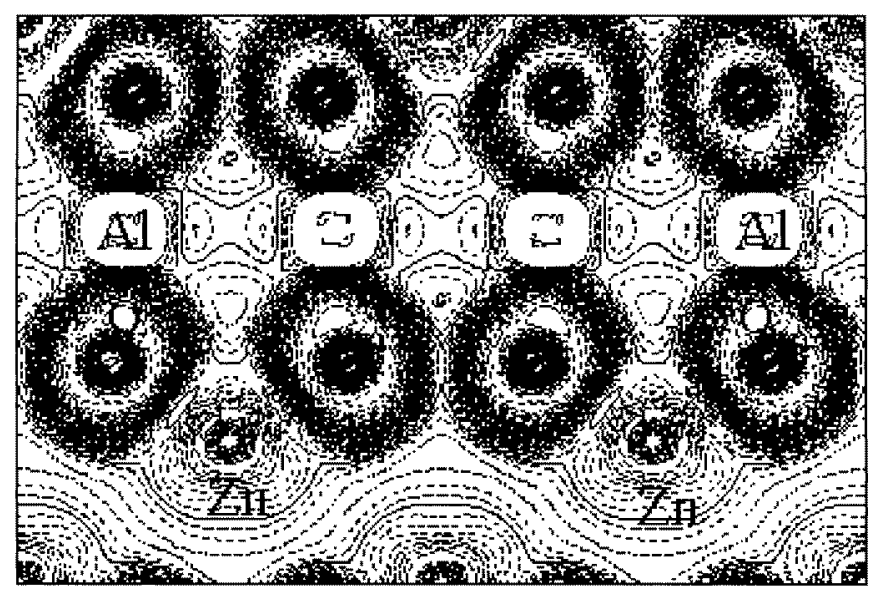

Figure 8. The ELF contour plot of $\mathrm{ZnAl}_{2} \mathrm{O}_{4}$ along the (110) plane.

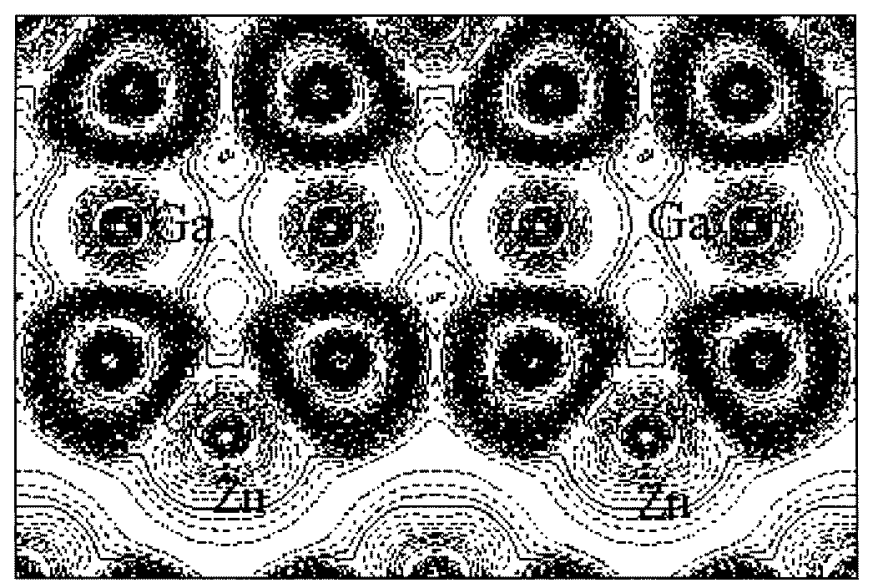

Figure 9. The ELF contour plot of $\mathrm{ZnGa}_{2} \mathrm{O}_{4}$ along the (110) plane.

localization for the spinels. It is suggested that such a channel would provide a diffusion path for ions in the spinel lattice [12].

\section{Summary}

We have studied the electronic structure of magnesium aluminate, zinc aluminate and zinc gallate spinels by means of the self-consistent tight-binding linearized muffin-tin orbital method with the atomic sphere approximation. The band structures along with the total and partial densities of states were used to analyse the details of the electronic properties.

Our study shows that the spinels, i.e. $\mathrm{MgAl}_{2} \mathrm{O}_{4}, \mathrm{ZnAl}_{2} \mathrm{O}_{4}$ and $\mathrm{ZnGa}_{2} \mathrm{O}_{4}$, are direct-bandgap materials with band gaps of $5.36 \mathrm{eV}, 4.11 \mathrm{eV}$ and $2.79 \mathrm{eV}$ respectively. The systematic lowering of the gaps at $\Gamma$ is due to the $3 \mathrm{~d}$ orbitals present in $\mathrm{ZnAl}_{2} \mathrm{O}_{4}$ and $\mathrm{ZnGa}_{2} \mathrm{O}_{4}$. The flat valence band indicates that the hole effective masses are rather large in these spinels. The electron effective masses are found to be similar for $\mathrm{MgAl}_{2} \mathrm{O}_{4}$ and $\mathrm{ZnAl}_{2} \mathrm{O}_{4}$ but considerably 
less for $\mathrm{ZnGa}_{2} \mathrm{O}_{4}$, suggesting a higher electron mobility in the gallate. The electron localization function contour plots clearly show that $\mathrm{MgAl}_{2} \mathrm{O}_{4}$ is more ionic than the zinc spinels.

\section{Acknowledgments}

The authors thank Dr James F Cordaro, QivaStar Incorporated, for helpful discussions. SS acknowledges financial assistance in the form of a graduate fellowship from Michigan Technological University. DGK would like to acknowledge partial support from the Department of Science and Technology, India.

\section{References}

[1] Hill R J, Craig J R and Gibbs G V 1979 Phys. Chem. Minerals 4317

[2] Sampath S K and Cordaro J F 1998 J. Am. Ceram. Soc. 81649

[3] Invented by Dr James F Cordaro while a member of the academic staff of Michigan Technological University. Licensed for research purposes to Michigan Technological University. Developed by Dr James F Cordaro of QivaStar Incorporated, Ridgecrest, CA, and Lynn E Long of Hughes Space and Communications Company, El Segundo, CA (patents pending).

[4] Itoh S, Toki H, Sato Y, Morimoto K and Kishino T 1991 J. Electrochem. Soc. 1381509

[5] Omata T, Ueda N and Ueda K 1994 Appl. Phys. Lett. 641077

[6] Cormack A N, Lewis G V, Parker S C and Catlow C R A 1988 J. Phy. Chem. Solids 4953

[7] Pandey R, Gale J D, Sampath S K and Recio J M 1999 J. Am. Ceram. Soc. submitted

[8] Andersen O K 1975 Phys. Rev. B 123020

[9] Andersen O K, Jepsen O and Sob M 1987 Electronic Band Structure Calculations and its Applications (Springer Lecture Notes in Physics 283) ed M Yussouff (Berlin: Springer) p 1

[10] Das G P 1992 Pramana 38545

[11] von Barth U and Hedin L 1972 J. Phys. C: Solid State Phys. 51629

[12] Xu Yong-Nian and Ching W Y 1991 Phys. Rev. B 434461

[13] Catti M, Valerio G, Dovesi R and Causà M 1994 Phys. Rev. B 4914179

[14] Bortz M L, French R H, Jones D J, Kasowski R V and Ohuchi F S 1990 Phys. Scr. 41537

[15] Wei S H and Zunger A 1988 Phys. Rev. B 378958

[16] Becke A D and Edgecombe K E 1990 J. Chem. Phys. 925397 